\title{
CORRIGENDUM
}

\section{Growing Fat on Reform: Obesity and Nutritional Disparities among China's Children, 1979-2005 - CORRIGENDUM}

Stephen L. Morgan

doi:10.1017/S030574101400112X, Published by Cambridge University Press, 20 November 2014.

In the article by Morgan (2014) there was an error in the headings of table 2. The correct table is republished here.

\section{References}

Morgan, Stephen L. 2014 "Growing Fat on Reform: Obesity and Nutritional Disparities among China's Children, 1979-2005.” The China Quarterly 220, 
Table 2: Change in Prevalence of Obesity among Chinese Aged 7-22, 1985-2005 (\%)

\begin{tabular}{|c|c|c|c|c|c|c|c|c|}
\hline & \multicolumn{4}{|c|}{ Urban Boys } & \multicolumn{4}{|c|}{ Rural Boys } \\
\hline & 1985 & 1995 & 2005 & Change $^{1}$ & 1985 & 1995 & 2005 & Change \\
\hline $7 \sim 9$ & 0.12 & 5.88 & 11.69 & 97.4 & 0.86 & 1.24 & 5.37 & 6.2 \\
\hline $10 \sim 12$ & 0.41 & 8.92 & 15.33 & 37.4 & 1.37 & 2.08 & 7.09 & 5.2 \\
\hline $13 \sim 15$ & 0.32 & 6.74 & 12.09 & 37.8 & 0.97 & 1.82 & 5.35 & 5.5 \\
\hline $16 \sim 18$ & 0.05 & 3.63 & 10.57 & 211.4 & 0.65 & 1.22 & 4.09 & 6.3 \\
\hline 19 22 & 0.03 & 0.88 & 7.20 & 240.0 & 0.53 & 0.81 & 3.43 & 6.5 \\
\hline \multirow[t]{3}{*}{ Mean $(p-w)^{2}$} & 0.19 & 5.08 & 11.39 & 59.9 & 0.88 & 1.45 & 5.07 & 5.8 \\
\hline & \multicolumn{4}{|c|}{ Urban Girls } & \multicolumn{4}{|c|}{ Rural Girls } \\
\hline & 1985 & 1995 & 2005 & Change & 1985 & 1995 & 2005 & Change \\
\hline $7 \sim 9$ & 0.55 & 2.32 & 5.18 & 9.4 & 0.55 & 0.74 & 2.97 & 5.4 \\
\hline $10 \sim 12$ & 0.80 & 4.04 & 8.08 & 10.1 & 0.80 & 1.64 & 4.24 & 5.3 \\
\hline $13 \sim 15$ & 0.64 & 3.91 & 6.33 & 9.9 & 0.64 & 1.74 & 3.07 & 4.8 \\
\hline $16 \sim 18$ & 0.33 & 1.58 & 3.69 & 11.2 & 0.33 & 0.76 & 1.63 & 4.9 \\
\hline 19 22 & 0.39 & 0.61 & 1.89 & 4.8 & 0.39 & 0.47 & 1.18 & 3.0 \\
\hline Mean $(p-w)^{2}$ & 0.53 & 2.55 & 5.01 & 9.5 & 0.33 & 1.09 & 2.63 & 8.0 \\
\hline
\end{tabular}

